\title{
El incidente de reparación integral oficioso de la Ley 1098 de 2006: ¿es realmente favorable para los menores de edad?*
}

\section{Alejandro Gaviria Cardona*}

\begin{abstract}
Resumen. El artículo 197 de la Ley 1098 de 2006, buscando la protección del interés superior del menor de edad, consagra para los jueces penales el deber de iniciar, de manera oficiosa, el incidente de reparación integral, siempre que haya sentencia condenatoria en contra de un mayor de edad, la víctima sea un menor de edad y su representante no lo inicie. El presente artículo analiza si el deber consiste solo en iniciar dicho incidente o, por el contrario, en tramitarlo hasta el final. Igualmente, se determina el alcance del fallo o del desinterés del representante de la víctima menor de edad, es decir, se establece si la decisión que pone fin al incidente hace tránsito a cosa juzgada, máxime en aquellos eventos en los cuales la víctima no formuló, de manera expresa, una pretensión resarcitoria de perjuicios o hubo una manifestación, tácita o expresa, de desistimiento.
\end{abstract}

Fecha de recepción: 21 de enero de 2020. Fecha de aceptación: 14 de agosto de 2020. Para citar el artículo: GAVIRIA CARDONA, A., "El incidente de reparación integral oficioso de la Ley 1098 de 2006: ¿es realmente favorable para los menores de edad?", Revista de Derecho Privado, Universidad Externado de Colombia, n. ${ }^{\circ}$ 40, enero-junio 2021, 545-554, Dor: https://doi.org/10.18601/01234366. n40.19.

** Universidad Eafit, Medellín, Colombia; docente de posgrado. Universidad Autónoma Latinoamericana, Medellín, Colombia; docente de pregrado y posgrado. Instituto Colombiano de Responsabilidad Civil y del Estado, Medellín, Colombia; miembro activo. Ivs Civile Salamanticense - Red Salmantina de Civilistas Latinoamericanos, Salamanca, España; miembro activo. Magíster en Derecho Procesal, Universidad de Medellín, Medellín, Colombia. Especialista en Responsabilidad Civil y Seguros, Universidad Eafit, Medellín Colombia. Abogado, Universidad de Medellín, Medellín, Colombia. Contacto: alejandro.gaviriac@hotmail.com Orcid: 0000-0002-6660-1699. 
PALABRAS Clave: incidente de reparación integral, interés superior, menor de edad, pretensión resarcitoria, indemnización de perjuicios, desistimiento, cosa juzgada.

\title{
Is the Integral Reparation Incident, Enshrined in Law 1098 of 2006 Beneficial for Minors?
}

\begin{abstract}
The Article 197 of Law 1098 of 2006, seeking the protection of the best interests of the minor, enshrines for criminal judges, the duty to initiate, in an informal manner, the incident of integral reparation, provided there is a conviction against an adult, the victim is a minor, and his representative does not initiate it. In this article we will try to analyze if the duty consists only in initiating or, on the contrary, processing until the end, said incident. Likewise, the scope of the judgment or the lack of interest of the representative of the minor victim will be determined, that is, it will be established if the decision that ends the incident, makes transit to a thing judged, especially, in those events in which the victim He did not expressly formulate a compensation claim for damages or there was a tacit or express manifestation of withdrawal.
\end{abstract}

KEYWORDS: incident of integral reparation, best interest, minor, compensation claim, compensation for damages, withdrawal, res judicata.

Sumario. Introducción. I. ¿El deber del juez consiste solo en iniciar el incidente de reparación integral de manera oficiosa o comprende, además, el de tramitarlo? ¿Y el trámite debe llegar a sentencia o se podrá declarar terminado de manera anticipada debido al desinterés de la víctima? II. ¿Cuál es el alcance del pronunciamiento judicial? III. ¿El fallo del incidente de reparación integral oficioso hace tránsito a cosa juzgada? Conclusiones. Referencias.

\section{Introducción}

El artículo 197 de la Ley 1098 de 2006, por la cual se expide el Código de la Infancia y la Adolescencia, consagra el deber de iniciar, de manera oficiosa, el incidente de reparación integral cuando se condene penalmente a un adulto, la víctima del delito sea un menor de edad y los padres, el representante legal o el defensor de familia no lo solicitaren dentro de los treinta días siguientes al proferimiento de la sentencia condenatoria.

La finalidad de la precitada ley es proteger, por encima de todo, los derechos de los menores de edad, tal y como se evidencia en las normas que a continuación se transcriben:

Artículo 1. ${ }^{\circ}$ Finalidad. Este código tiene por finalidad garantizar a los niños, a las niñas y a los adolescentes su pleno y armonioso desarrollo para que crezcan en el seno 
de la familia y de la comunidad, en un ambiente de felicidad, amor y comprensión. Prevalecerá el reconocimiento a la igualdad y la dignidad humana, sin discriminación alguna.

Artículo 2. ${ }^{\circ}$ Objeto. El presente código tiene por objeto establecer normas sustantivas y procesales para la protección integral de los niños, las niñas y los adolescentes, garantizar el ejercicio de sus derechos y libertades consagrados en los instrumentos internacionales de Derechos Humanos, en la Constitución Política y en las leyes, así como su restablecimiento. Dicha garantía y protección será obligación de la familia, la sociedad y el Estado.

Artículo $8 .^{\circ}$ Interés superior de los niños, las niñas y los adolescentes. Se entiende por interés superior del niño, niña y adolescente, el imperativo que obliga a todas las personas a garantizar la satisfacción integral y simultánea de todos sus Derechos Humanos, que son universales, prevalentes e interdependientes.

Artículo 9. ${ }^{\circ}$ Prevalencia de los derechos. En todo acto, decisión o medida administrativa, judicial o de cualquier naturaleza que deba adoptarse en relación con los niños, las niñas y los adolescentes, prevalecerán los derechos de estos, en especial si existe conflicto entre sus derechos fundamentales con los de cualquier otra persona.

En caso de conflicto entre dos o más disposiciones legales, administrativas o disciplinarias, se aplicará la norma más favorable al interés superior del niño, niña o adolescente.

De la lectura de los anteriores artículos se desprende que el interés superior del menor es el norte que debe guiar todas las actuaciones en donde haya de por medio algún niño, niña y/o adolescente, es decir, se debe tender a esta efectividad, y por ello se consagró la referida obligación de iniciar, de manera oficiosa, el incidente de reparación integral: para proteger a los menores de edad, en tanto, además de sancionarse penalmente al responsable, se busca el pleno resarcimiento de todos los perjuicios sufridos por aquellos.

Una lectura desprevenida del precitado artículo 197 lleva a pensar que, efectivamente, mediante el inicio oficioso del incidente de reparación integral se logra una adecuada protección del menor de edad. Una segunda lectura, ya de manera más reflexiva, conduce a la formulación de los siguientes interrogantes: ¿el deber del juez es solo de iniciar el incidente o comprende, además, la de tramitarlo?, ¿el trámite debe llegar a sentencia o se podrá declarar terminado de manera anticipada en razón del desinterés de la víctima?, ¿cuál es el alcance del pronunciamiento judicial?, y, por último, ¿ese fallo hace tránsito a cosa juzgada? El presente escrito intenta dar respuesta a cada uno de estos interrogantes. 


\section{I. ¿El deber del juez consiste solo en iniciar el incidente de reparación integral de manera oficiosa o comprende, además, el de tramitarlo? ¿Y el trámite debe llegar a sentencia o se podrá declarar terminado de manera anticipada en razón del desinterés de la víctima?}

El artículo 317 del código general del proceso (c.g.p.) consagra el desistimiento tácito, y en el literal h establece que no aplicará para los incapaces cuando carezcan de apoderado judicial.

En este punto se deben resaltar dos aspectos: entendemos que ante el desinterés del afectado o sus representantes para iniciar el incidente de reparación integral, lo más plausible es que carezca de apoderado judicial que lo represente en el trámite del mismo, razón por la cual no le sería permitido al juez penal terminar la actuación por desistimiento tácito.

De otro lado, se recuerda la protección especial que busca ser brindada a los menores de edad por intermedio de la Ley 1098 de 2006, la cual, al consagrar el inicio oficioso del incidente de reparación integral, tácitamente está ordenando que el mismo se tramite hasta el fin y no se agote en formalismos que buscan descongestionar el aparato judicial.

Ahora, pese a que del tenor literal del artículo 197 de la Ley 1098 de 2006 se desprende la obligación de iniciar el incidente, será deber del juez tramitarlo hasta el fin, lo cual implica que deberá decidir de fondo el conflicto, lo que para el caso en concreto consiste en decidir acerca de la obligación indemnizatoria a cargo del responsable.

Esto de cara al precitado interés superior del menor, en tanto, si la facultad del juez se limitara a darle inicio o apertura al incidente, pero no a tramitarlo, no se estaría cumpliendo su finalidad. Nótese que con solo iniciar el incidente no se logra el cometido del mismo: la reparación integral del menor de edad víctima del delito.

De otro lado, en caso de desistimiento expreso por parte del representante del menor de edad -o manifestación de voluntad similar, encaminada a dar por terminado el incidente de reparación integral-, de acuerdo con lo preceptuado en el artículo 315 c.g.p. y a la finalidad de la norma previamente referenciada, no le será permitido al juez autorizar dicha terminación.

Recuérdese que, en cumplimiento de la protección del interés superior del menor, mediante el incidente de reparación integral, lo que se busca es que aquel sea resarcido en todos los perjuicios sufridos por el delito, y la manifestación de desinterés o desistimiento, según el artículo 314 c.g.p., implica renuncia a la pretensión, lo cual implicará que, con posterioridad, no podrá iniciar otra reclamación, por cuanto se entiende que su pretensión fue resuelta desfavorablemente.

Luego, permitirle al representante legal del menor desistir de la pretensión indemnizatoria desnaturalizaría la finalidad por la cual el legislador consagró el incidente de reparación oficioso. 


\section{II. ¿Cuál es el alcance del pronunciamiento judicial?}

Lo dicho hasta ahora pareciera ratificar, efectivamente, que la norma bajo estudio fue creada para proteger el interés superior de los menores de edad y que, además, es eficaz de cara al logro del objetivo.

Pero, al analizarse detalladamente la situación, se evidencia que esto por sí solo puede generar más problemas que ventajas. Veamos.

La finalidad del incidente de reparación integral es buscar el resarcimiento de la víctima afectada con el delito, pero en el curso del proceso penal, para lo cual es indispensable que se haya proferido sentencia condenatoria en contra del acusado (ahora condenado); de lo contrario, no procederá el incidente. Ahora bien, se precisa que, de no cumplirse este requisito, las víctimas podrán iniciar un proceso civil de cara al resarcimiento. Es decir, no se exige de un delito para que proceda la reparación en virtud de la responsabilidad civil, aunque, se itera, para iniciar el incidente de reparación integral sí es indispensable sentencia condenatoria por el delito en contra del responsable ${ }^{1}$.

El fallo del incidente debe comprender un pronunciamiento expreso acerca de todos y cada uno de los perjuicios sufridos por la víctima, lo cual exige una ardua tarea probatoria de su parte, salvo en eventos de perjuicios extrapatrimoniales, los cuales se presumen, no solo en cabeza de la víctima directa sino también de algunas indirectas.

En este punto debemos preguntarnos: ¿frente a cuáles perjuicios se debe pronunciar el juez penal? La decisión del incidente de reparación integral debe comprender todos los perjuicios, tanto patrimoniales ${ }^{2}$ como extrapatrimoniales $^{3}$, toda vez que, en aquellos eventos en donde el legislador no distingue, no le es dable al operador distinguir ${ }^{4}$.

1 Piénsese, por ejemplo, en un supuesto de daño en bien ajeno culposo. En este supuesto no se configura el delito, en tanto este solo procede en la modalidad dolosa, razón por la cual no se proferirá sentencia condenatoria penal en contra del actor. No obstante, el afectado podrá iniciar, vía civil, la búsqueda de la reparación.

2 Los perjuicios patrimoniales son aquellos verificables y cuantificables de forma objetiva. En ese sentido, véase Isaza Posse, M. C., De la cuantificación del daño. Manual teórico práctico, Medellín, Temis, 2015, 21, quien indicó que el perjuicio patrimonial está dado "por las consecuencias o repercusiones del daño en la esfera económica del reclamante. La medida de esas consecuencias en su patrimonio determina el alcance o el valor del derecho que debe ser indemnizado por concepto de perjuicio patrimonial".

3 Entendiendo por estos, aquellos que "no tienen una naturaleza económica, en el sentido de que, por definición, no se les puede medir en dinero". HenaO, J. C., El daño, Bogotá, Universidad Externado de Colombia, 1998, 230.

4 Prescribe el artículo 27 c.c. colombiano: "Cuando el sentido de la ley sea claro, no se desatenderá su tenor literal a pretexto de consultar su espíritu. Pero bien se puede, para interpretar una expresión oscura de la ley, recurrir a su intención o espíritu, claramente manifestados en ella misma o en la historia fidedigna de su establecimiento". 
Se tiene entonces que, frente a los perjuicios extrapatrimoniales, aquellos denominados morales y vida de relación ${ }^{5}$, el juez no tendrá mayores problemas prácticos, toda vez que estos, tal y como se indicó, se presumen en cabeza tanto de la víctima directa como de algunas víctimas indirectas ${ }^{6}$, como por ejemplo, cónyuge, compañero(a) permanente, padres, hijos, entre otros; mientras que, tratándose de los perjuicios patrimoniales: lucro cesante, daño emergente o pérdida de oportunidad ${ }^{7}$ sufrida por la víctima, se le exige al reclamante que acredite cada uno de los elementos que lo configuran.

Con relación al daño emergente, en tanto consiste en gastos o erogaciones y, en general, en la "disminución del patrimonio"8 , que, en este caso, haya sufrido la víctima en razón del delito, debe probarse, además del indicado gasto o de la necesidad futura, su relación de causa-efecto con el ilícito penal. Por ejemplo, si en razón de una lesión corporal la víctima requiere de cierto tipo de alimentación o de pañales, de terapia física o sicológica, debe probarse, además de la necesidad del gasto, que estos fueron recetados por la lesión derivada del delito y no por otras razones, que, incluso, pueden coincidir temporal o circunstancialmente con la lesión.

Frente al lucro cesante, debe acreditarse que el delito privó a la víctima de los ingresos que el bien dañado le proporcionaba o que, en razón de la lesión causada, no pudo continuar ejerciendo la actividad lucrativa que desempeñaba ${ }^{9}$, o que, en el futuro, no la podrá realizar, para lo cual se exige prueba del porcentaje de pérdida de capacidad laboral, así como de los ingresos.

Ahora, tratándose de menores de edad, como en el presente análisis, el lucro cesante, si al momento de la lesión no devengaba ingresos con la respectiva autorización del Ministerio del Trabajo ${ }^{10}$, se deberá desde el momento en el cual cumpla dieciocho años, con base en el salario mínimo legal mensual vigente al momento de la reparación, aunque ello implique realizar un descuento financiero por el pago anticipado $^{11}$, siempre y cuando se acredite, efectivamente, la secuela de carácter permanente y su incidencia tanto en la vida diaria como en la vida laboral.

En los supuestos de pérdida de la oportunidad, la actividad probatoria también exige que el reclamante pruebe que tenía posibilidades de evitar un perjuicio o de

5 Gaviria Cardona, A., Guía teórico-práctica para la cuantificación de perjuicios, Medellín, Fondo Editorial Universidad EAFIT, 2017, 21-35.

6 Ibíd., 22.

7 Ibíd., 39-59.

8 Le Tourneau, P., La responsabilidad civil, J. Tamayo Jaramillo (trad.), Bogotá, Legis, 2010, 70.

9 Trigo Represas, F. y López Mesa, M., Cuantificación del daño, vol. 5 del Tratado de la responsabilidad civil, Buenos Aires, La Ley, 2006, 77.

10 En este sentido, véanse los artículos 35 y 113 a 118 de la Ley 1098 de 2006.

11 Gaviria Cardona, A., "Disminución de la indemnización para los hijos por el aporte causal de los padres en la producción del daño y lucro cesante de menores de edad. Análisis de la Sentencia sc16690 de 2016 de la Corte Suprema de Justicia”, Revista de Derecho Privado, Universidad Externado de Colombia, n. ${ }^{\circ} 33,2017,251-263$. 
obtener un beneficio pero que, en razón del delito, esta posibilidad se truncó y, en este momento, no existe forma alguna que permita establecer si la situación final se iba o no a presentar ${ }^{12}$.

Nótese que, en todos los eventos de perjuicios patrimoniales, a la víctima se le exige una labor probatoria y solo en determinados eventos contará con presunciones a su favor: por ejemplo, si la persona logra demostrar que era productiva pero no el valor de sus ingresos, se le presumirá el salario mínimo, o, tal y como se indicó, en supuestos de menores de edad, si la secuela es de tipo permanente, se le presume que dejará de percibir el salario mínimo legal mensual vigente -o el porcentaje en proporción a la pérdida de capacidad laboral-, siempre y cuando se establezca su edad, su vida probable, el porcentaje de pérdida de capacidad laboral, entre otros.

Es precisamente en este sentido, de cara a la solución del conflicto planteado por medio del incidente de reparación integral, que el juez deberá resolver de fondo acerca de todos los perjuicios, aunque no haya prueba de los mismos, caso en el cual la decisión deberá ser desestimatoria de la pretensión, en razón de la carga probatoria que recae sobre la víctima-reclamante, la cual se encuentra consagrada en el artículo 167 c.g.p.

\section{III. ¿El fallo del incidente de reparación integral oficioso hace tránsito a cosa juzgada?}

En este punto es necesario precisar que si bien el acto procesal de apertura, que es el consagrado en la norma, es diferente al acto procesal de formular la pretensión, tal y como se indicó, debe entenderse, bajo una interpretación sistemática y teleológica, que lo que se busca con la apertura del incidente de reparación integral es resarcir al menor de todos los perjuicios que hubiere sufrido con el delito, lo cual no se logra con la sola apertura del incidente, por lo que el mismo deberá tramitarse hasta la decisión de fondo; razón por la cual se entiende que, para este caso en concreto, la pretensión de parte -entiéndase del menor de edad víctima- es una pretensión genérica de ser resarcido, la cual existe en virtud de la ley y no requiere ningún acto procesal de la parte misma, todo, se insiste, para proteger ese interés superior del menor, al cual previamente se ha hecho referencia.

Siendo así, si la víctima no prueba el perjuicio, ni el quantum del mismo, deberá el juez de la causa desestimar la pretensión indemnizatoria, decisión que, sin lugar a dudas, hará tránsito a cosa juzgada, entendiendo por esta la solución al conflicto

12 Para un estudio detallado acerca de la pérdida de la oportunidad, véase CHABAs, F., "La pérdida de una oportunidad ('chance') en el derecho francés de la responsabilidad civil", Responsabilidad Civil $y$ del Estado, n. ${ }^{\circ} 33,2013,23-44$. 
intersubjetivo de intereses, motivo por el cual se extingue, y se prohíbe a los sujetos procesales volver sobre el asunto ${ }^{13}$, incluso por otros medios.

Significa lo anterior, entonces, que la decisión adoptada por el juez es firme, al punto que no puede volver a ser discutida (inmutabilidad o inmodificabilidad de la sentencia), y, además, que esta debe ser cumplida a cabalidad (efectividad de la sentencia): "la cosa juzgada no es solamente una calificación de inmutabilidad de la sentencia, pues debe referirse también a la eficacia del contenido. Por eso se alude al caso juzgado e implica la consideración que de esta manera ocupa el resultado del proceso en el universo jurídico" 14 .

Luego, el juez penal, al resolver el incidente de reparación de perjuicios, debe pronunciarse de fondo sobre la configuración o no de los perjuicios sufridos por el menor de edad víctima, así como del respectivo valor indemnizatorio.

Esta decisión, al hacer tránsito a cosa juzgada, impide que con posterioridad las víctimas acudan a otras instancias judiciales, de cara a buscar el resarcimiento de los perjuicios derivados del ilícito, a menos que se trate de situaciones que se hayan presentado con posterioridad a la sentencia.

Es apenas lógico que si ya un órgano jurisdiccional se pronunció con relación a la existencia y cuantificación de los perjuicios sufridos por la víctima, no sea posible, con posterioridad, volver a debatir el mismo asunto, salvo que, se insiste, se trate de hechos no debatidos, por tratarse de hechos presentados después de haberse proferido la sentencia.

Esto, cuando el menor de edad víctima ha sido correctamente representado durante el incidente de reparación integral, no presenta ninguna problemática, en tanto se asume que el letrado cumplió a cabalidad con su labor, incluyendo la debida y correcta prueba tanto del perjuicio como de su valor; pero, cuando el incidente se ha iniciado de manera oficiosa, es de suponerse que no hay apoderado que asuma dicha labor, razón por la cual la decisión del juez, de cara a la carga de la prueba, deberá consistir en un fallo desestimatorio de la pretensión indemnizatoria, con la consabida consecuencia de la prohibición de acudir nuevamente la jurisdicción, en tanto su decisión hizo tránsito a cosa juzgada.

Nótese cómo el legislador, de cara a la protección del interés superior de los menores de edad, al consagrar el inicio del incidente de reparación integral en favor del menor, realmente le está generando un perjuicio, en tanto si este no cumple con sus cargas probatorias, la decisión del juez penal, salvo que hubiese alguna presunción, deberá ser desestimatoria de la pretensión indemnizatoria, imposibilitándose, de esta forma, que la víctima pueda acudir, con posterioridad, a otras instancias judiciales en virtud de la cosa juzgada.

13 Quintero, B. y Prieto, E., Teoría general del derecho procesal, 4. a ed., Bogotá, Temis, 2008, 582, quienes indican que "la cosa juzgada en sentido sustancial es la eficacia normativa de la declaración de certeza jurisdiccional: la regla concreta, la ley de la situación definida, el caso juzgado". 
En este sentido, son evidentes los diversos conflictos generados con la norma bajo análisis, por lo que debe desaparecer del ordenamiento jurídico, en tanto, se insiste, pese a que teóricamente busca la protección del interés superior del menor de edad, en la práctica lo que hace es generar mayores afectaciones al menor de edad víctima.

En este punto debe ponerse de presente que el 30 de octubre de 2019 se radicó en el Senado de la República el Proyecto de Ley 235, el cual buscaba modificar el código de procedimiento penal y, concretamente, en su artículo 16, suprimía el incidente de reparación integral. Al respecto se indica que el referido proyecto ha sido archivado, de conformidad con lo dispuesto en los artículos 160 de la Ley 5 de 1992 y 162 de la Constitución Política, según consta en la página web oficial: http://www. secretariasenado.gov.co/index.php/proyectos-de-ley-2015 ${ }^{[15]}$.

\section{Conclusiones}

La finalidad del inicio oficioso del incidente de reparación integral es proteger el interés superior del menor, toda vez que, además de sancionarse al responsable penalmente por su actuación, se busca que los perjuicios sufridos por la víctima menor de edad sean plenamente resarcidos.

Si el menor de edad no cuenta con representante legal en el curso del proceso, no procederá el desistimiento tácito.

De otro lado, en caso de desistimiento expreso por parte del representante del menor de edad -o manifestación de voluntad similar, encaminada a dar por terminado el incidente de reparación integral-, no podrá el juez autorizar dicha terminación, toda vez que ello iría en contravía de la finalidad de la norma: protección del interés superior del menor.

Lo que se busca con la apertura del incidente de reparación integral es resarcir al menor de edad de todos los perjuicios que hubiere sufrido con el delito. Ello implica que la pretensión de parte, es una pretensión genérica de ser resarcido, la cual existe en virtud de la ley y no requiere ningún acto procesal de la parte misma.

El fallo del incidente debe comprender un pronunciamiento expreso acerca de todos y cada uno de los perjuicios sufridos por la víctima, bien sea reconociéndolos o desestimándolos.

Luego, si la víctima no prueba el perjuicio, ni el quantum del mismo, deberá el juez penal desestimar la pretensión indemnizatoria, decisión que, sin lugar a dudas, hará tránsito a cosa juzgada, prohibiéndose, de esta forma, que los sujetos procesales vuelvan sobre el asunto. 


\section{Referencias}

Chabas, F., "La pérdida de una oportunidad ('chance') en el derecho francés de la responsabilidad civil”, Responsabilidad Civil y del Estado, n. ${ }^{\circ} 33,2013,23-44$.

Gaviria Cardona, A., "Disminución de la indemnización para los hijos por el aporte causal de los padres en la producción del daño y lucro cesante para menores de edad. Análisis de la sentencia SC-16690 de 2016 de la Corte Suprema de Justicia”, Revista de Derecho Privado, Universidad Externado de Colombia, n. ${ }^{\circ} 33$, 2017, 251-263.

Gaviria Cardona, A. Guía teórico-práctica para la cuantificación de perjuicios, Medellín, Fondo Editorial Universidad EAFIT, 2017.

Henao, J. C. El daño, Bogotá, Universidad Externado de Colombia, 1998.

Isaza Posse, M. C. De la cuantificación del daño. Manual teórico práctico, Medellín, Temis, 2015.

Le Tourneau, P. La responsabilidad civil, J. Tamayo Jaramillo (trad.), Bogotá, Legis, 2010 .

Quintero, B. y Prieto, E. Teoría general del derecho procesal, 4. ed., Bogotá, Temis, 2008.

Trigo Represas, F. y López Mesa, M. Tratado de la responsabilidad civil. Cuantificación del daño, vol. 5, Buenos Aires, La Ley, 2006.

\section{Normatividad}

Código civil.

Código general del proceso.

Constitución Política de Colombia.

Ley 5 de 1992.

Ley 1098 de 2006. 